\title{
IDENTIFICAÇÃO DAS OCUPAÇÕES IRREGULARES NOS FUNDOS DE VALE DA CIDADE DE LONDRINA/PR POR MEIO DE IMAGEM LANDSAT 7
}

\author{
Identification of the irregular occupations in the bottom of valley \\ in the city of Londrina, using the image landsat 7
}

\author{
Mirian Vizintim Fernandes BARROS ${ }^{1}$ \\ Akacia SCOMPARIM ${ }^{2}$ \\ Celso Satoshi KISHI ${ }^{3}$ \\ João Henrique CAVIGLIONE ${ }^{4}$ \\ Márcia Regina Lopes ARANTES 5 \\ Sandra Yoshimi NAKASHIMA ${ }^{6}$ \\ Teresinha Esteves da Silveira REIS ${ }^{7}$
}

\begin{abstract}
RESUMO
Londrina é uma cidade de porte médio com grau de urbanização acentuado no contexto paranaense. Atualmente existem vários conflitos de ordem social e ambiental, como é o caso da ocupação irregular em fundos de vale, objeto de estudo deste trabalho. Foram utilizados dados cartográficos do Banco de Dados do SIG-Londrina, do grupo IMAP\&P do Departamento de Geociências da UEL, os quais foram processados no SPRING. Os mapas derivados gerados foram os de restrição legal e de áreas de preservação ocupadas irregularmente. Os resultados apontam a existência de $21,36 \mathrm{~km}^{2}$ de área de preservação permanente, sendo que $5,42 \mathrm{~km}^{2}(25,4 \%)$ encontram-se com ocupação irregular.
\end{abstract}

\section{Palavras-chave:}

Áreas de proteção permanente, sensoriamento remoto, sistema de informações geográficas, ocupação urbana.

\begin{abstract}
Londrina is a medium size city, with a high urbanization stage for the state of Paraná context. Nowadays there are many social and environmental conflicts, the irregular occupation of margins of rivers (bottom of valley) studied in this paper is a typical example. Using the cartographic data of the database of SIG-Londrina, by IMAP\&P group, in the Geosciences Department of UEL, the maps were processed by SPRING. Then maps of legal restriction and environmental protection areas with human occupation were generated. The results show the existence of $21,36 \mathrm{~km}^{2}$ of environmental protection area (area of permanent preservation), but $5,42 \mathrm{~km}^{2}(25,4 \%)$ of that area are irregularly occupied by urbanization.
\end{abstract}

\section{Key words:}

Permanent protection areas, geographic information system, urban occupation, remote sensing.

\footnotetext{
1 Profa. Dra. do Departamento de Geociências da Universidade Estadual de Londrina - vizintim@uel.br. 2 Mestranda em Geografia, Meio Ambiente e Desenvolvimento, Universidade Estadual de Londrina - Akascom@uel.br 3 Mestrando em Geografia, Meio Ambiente e Desenvolvimento, Universidade Estadual de Londrina - geokishi@uol.com.br 4 Mestrando em Geografia, Meio Ambiente e Desenvolvimento, Universidade Estadual de Londrina - caviglione@iapar.br 5 Mestranda em Geografia, Meio Ambiente e Desenvolvimento, Universidade Estadual de Londrina 6 Mestranda em Geografia, Meio Ambiente e Desenvolvimento, Universidade Estadual de Londrina 7 Doutoranda em Agronomia - Universidade Estadual de Londrina - reis@ffalm.br
} 


\section{INTRODUÇÃO}

O crescimento acelerado da população e da urbanização é na atualidade uns dos problemas graves da humanidade, sendo visto como uma das principais causas da deterioração do meio ambiente, pois a concentração humana e de suas atividades provoca ruptura do funcionamento do ambiente natural (CAVALHEIRO, 1991).

De acordo com MILANO (1990), embora o meio urbano não apresente padrões de qualidade ambiental desejáveis para uma vida saudável, existem mais de $80 \%$ da população mundial morando nas cidades. As condições ambientais das cidades criam uma natureza hostil, pois o desequilíbrio entre os elementos que compõem o sistema urbano compromete a qualidade de vida de seus habitantes (CARRARA, et al. 1991).

No processo de urbanização ocorre a substituição do ecossistema natural por um outro completamente adverso, que o homem organiza conforme suas necessidades de sobrevivência, e segundo o poder que exerce sobre este espaço. O uso intensivo do solo e a ausência de planejamento pelas atividades urbanas tem gerado disfunções espaciais e ambientais, repercutindo na qualidade de vida do homem, que se dá de modo diferenciado, atingindo na maioria das vezes de forma mais intensa a população de baixa renda, a qual, muitas vezes sem acesso a moradia, passa a ocupar áreas impróprias à habitação, como por exemplo as Áreas de Proteção Permanente - (APPs). A ocupação irregular destas áreas não ocorre apenas por invasões, mas pode estar associada a aprovação indevida de loteamento, falta de legislação, etc.

São consideradas APPs áreas que margeiam os cursos d'água (rio, nascente, lago, represa), encosta, local de declividade superior a $100 \%$ ou $45^{\circ}$ e outras situações quando declaradas pelo poder público, como para atenuar a erosão das terras, formar faixas de proteção ao longo de rodovias e ferrovias, proteger sítios de excepcional beleza ou de valor (científico ou histórico) ou ainda para assegurar condições de bem-estar público.

A ocupação irregular em áreas de fundos de vale ocorre em muitas cidades brasileiras de médio e grande porte. É um problema bastante grave, pois não se trata apenas da preservação ambiental destas áreas, mas é sobretudo um problema socioeconômico que reflete as questões de moradia do país e atinge diretamente uma parcela da população que não tem acesso a este direito.

Identificar, localizar e quantificar estas áreas são tarefas importantes para subsidiar o planejamento urbano relacionado à ocupação e ao uso do solo. Tendo em vista esta problemática foi desenvolvido o presente trabalho, na disciplina de Geoprocessamento Aplicado à Análise Ambiental, no Curso de Mestrado em Geografia, Meio Ambiente e Desenvolvimento da Universidade Estadual de Londrina objetivando identificar as áreas de fundos de vale na cidade de Londrina com ocupação ilegal. Situada no Norte do Paraná, é a segunda cidade mais importante do estado e a terceira do Sul do país. Cidade de porte médio, com mais de 450 mil habitantes, apresenta alto grau de urbanização em relação às demais cidades da região. Exerce uma área de influência considerável, sendo atrativa aos pequenos centros que estão em seu entorno, exercendo papel de metrópole regional. Seu rápido crescimento populacional e expansão desordenada no núcleo urbano causaram inúmeros problemas e conflitos de ordem social e ambiental, entre eles a ocupação de fundos de vale.

O desenvolvimento de instrumentos e técnicas de observação, análise e representação de dados espaciais tem contribuído para os estudos do espaço geográfico, pois permite maior rapidez no processamento, visualização e análise dos dados. Os Sistemas de Informações Geográficas (SIGs) são um exemplo que vem sendo utilizado em diversas áreas do conhecimento.

A capacidade de armazenar, recuperar dados (tabulares, gráficos ou setoriais), flexibilizar a manutenção dos dados e as várias possibilidades de visualização, características de um SIG, qualificam-no como uma ferramenta versátil e útil na análise do espaço geográfico e no apoio à tomada de decisões, principalmente em áreas urbanas, onde o volume de dados manipulado é muito grande (BARROS, 1998).

No desenvolvimento deste trabalho foi elaborada uma base cartográfica a partir de dados digitais existentes no SIG-LONDRINA, atualizados com novos dados obtidos a partir de imagens orbitais e cruzamento de dados, utilizando o SPRING, versão 3.5.1, desenvolvido pelo Instituto Nacional de Pesquisas Espaciais INPE.

\section{LEGISLAÇÃO AMBIENTAL SOBRE ÁREAS DE PRESERVAÇÃO PERMANENTE DE FUNDOS DE VALE}

Várias são as legislações que tratam da preservação das áreas que margeiam os corpos d'água, as chamadas Áreas de Preservação Permanente - APP, já que sua preservação e conservação é de extrema importância para o equilíbrio ambiental e para a qualidade da água dos rios.

A principal legislação ambiental que visa à proteção dessas áreas é a Lei Federal 4.771/65, chamada de Código Florestal, alterada pela Lei $n . ⒎ 803 /$ 
89. Esta lei define em seu art. $2^{\circ}$ que as faixas ribeirinhas devem ter no mínimo 30 metros de largura quando a largura do rio não ultrapassar 10 metros, aumentando conforme a largura do corpo d'água. No caso de ocupação destas áreas, a norma estabelecida através da Medida Provisória 1956-53 de agosto de 2000, que alterou o art. 4ํ do Código Florestal, dita que a supressão de vegetação em APPs e conseqüentemente a sua utilização só poderá ser efetuada para fins de utilidade pública e/ou benefício social devidamente declarado pelo poder público municipal.

Outro instrumento legal de grande importância na proteção do meio ambiente em áreas urbanas é o Plano Diretor dos Municípios, instituído pela Lei 7.483/98 de julho/2000, que traça diretrizes gerais para 0 planejamento global da cidade e dita normas para a proteção dos fundos de vale. Em Londrina, as leis de parcelamento do solo para fins urbanos de uso, ocupação e expansão urbana (aprovadas em 07/1998) definem as áreas de fundo de vale como "Áreas Especiais de Fundo de Vale e de Preservação Ambiental", devendo ser respeitadas as áreas ao longo das margens dos corpos d'água, numa largura mínima de 30 metros de cada lado. Esses locais teriam como princípio a proteção dos corpos d'água e destinar-se-iam prioritariamente à formação de parques contínuos, visando à preservação ambiental e à recreação.

Os fundos de vale situados em rios que são mananciais de abastecimento mereceram por parte do governo estadual uma lei que se preocupa com a sua preservação, a de $n . .8 .935 / 89$, que define algumas exigências especiais para os empreendimentos ou atividades que porventura venham a ser efetivados nas proximidades dos mananciais de abastecimento público. Neste caso específico consideram-se não só as APPs como também o seu entorno, de acordo com uma avaliação técnica do órgão ambiental competente.

Em se tratando de empreendimentos ou atividades potencialmente poluidoras e/ou utilizadores de recursos naturais, a Lei Federal n. ${ }^{\circ}$ 6.938/81 institui a obrigatoriedade de licenciamento ambiental para os empreendimentos que de alguma forma venham a alterar o meio ambiente, sendo obrigatória a elaboração do EIA - Estudo de Impacto Ambiental.

Popularmente mais conhecida como mata ciliar, a vegetação riparia se desenvolve ao longo dos rios, mananciais, reservatórios e demais corpos d'água e está entre os ecossistemas mais perturbados pela ação antrópica. Funciona como reguladora do fluxo de água, sedimentos e nutrientes entre os ecossistemas aquático e terrestre e é essencial para a proteção do solo e dos recursos hídricos (MENDONÇA; BARROS, 2002).
Legalmente, a vegetação riparia é parte da Área de Preservação Permanente, na qual é vedado o corte de vegetação nativa ou qualquer outra forma de exploração, definida pelo Código Florestal, lei federal $n . .4 .771 / 65$, devendo ser respeitadas as faixas marginais ao longo das margens dos rios, tendo estas larguras variáveis dependendo da largura dos corpos d'água. Ainda a Lei de Crimes Ambientais (n. 9.065/98) considera crime destruir ou danificar floresta considerada de preservação permanente, mesmo que em formação, bem como utilizá-la de forma indevida.

A vegetação marginal aos corpos d' água (riparia) tem recebido nos últimos anos atenção especial sobre questões relacionadas, dentre outras, à sua importância para a manutenção do equilíbrio do ecossistema aquático; às caracterizações quanto a florística; à estrutura genética de suas populações, ou ainda de questões referentes à revegetação de áreas riparias degradadas (SOARES, 2000).

A preservação da vegetação riparia é fundamental para a proteção de córregos e rios, principalmente os que atravessam as cidades, pois estão sujeitos a um elevado grau de intervenção antrópica. Tal vegetação contribui para a estabilização das margens dos corpos d'água, reduzindo o assoreamento e auxiliando na manutenção da qualidade da água. Juntamente com a vegetação localizada em outras áreas, atua sobre os elementos climáticos (em microclimas urbanos), contribuindo para o controle da radiação solar, temperatura e umidade do ar, a velocidade dos ventos e a ação das chuvas (ZANINI, 1998), além de reduzir a propagação de ruídos.

Além das funções de estabilizar as margens dos rios e córregos, manutenção da qualidade da água e atenuação de fatores climáticos, devem ser acrescentada para os fundos de vale sua importância em relação à fauna e flora nativa.

A preocupação com a preservação dos fundos de vale não é um mero capricho dos estudiosos, governantes e até da própria população. É antes de tudo uma necessidade a fim de se preservar e tentar recuperar a qualidade da água dos rios. Já é notório que a água é um dos elementos da natureza essenciais à vida e como tal merece todo o cuidado na sua conservação. Foi nesta linha de pensamento que o governo federal criou a Lei Nacional de Recursos Hídricos n. 9.433/97, que, além de traçar normas e diretrizes para o uso racional dos recursos hídricos, determina o pagamento de taxas pelo uso da água. 


\section{MATERIAL E MÉTODO}

A área urbana de Londrina corresponde a aproxi-

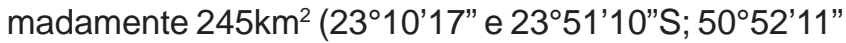
e 51'14'35”W) e está situada no norte do Estado do Paraná, na porção inferior da bacia do rio Tibagi. Seu relevo é recortado por diversos fluxos hídricos de pequeno porte e apresenta variação altimétrica aproximada de 380 a 750m. Segundo o Censo de 2000, publicado pelo Instituto Brasileiro de Geografia e Estatística (IBGE), vivem na área urbana de Londrina $97 \%$ da população do município, ou seja, 433.369 pessoas.

O Banco de Dados do SIG-LONDRINA, elaborado pelo Grupo Imagens, Paisagens e Personagens (IMAP\&P) do Departamento de Geociências da Universidade Estadual de Londrina (UEL), contém a base cartográfica da cidade de Londrina, base altimétrica de isocotas na escala 1:20.000 de eqüidistância de 5 metros, malha hidrográfica e carta do perímetro urbano (cedida pelo Instituto de Pesquisa e Planejamento Urbano de Londrina - IPPUL) e imagem do LANDSAT-7, sensor ETM+, Cena de 22 de julho de 1999, com a localização da órbita ponto em WRS 222_76, cedido pelo Instituto Nacional de Pesquisas Espaciais (INPE), para estudos na Universidade Estadual de Londrina (UEL), Departamento de Geociências.

Todo o processamento de dados foi realizado por meio do software SPRING - (Sistema de Processamento de Informações Georreferenciadas), versão 3.5.1, desenvolvido pelo Instituto Nacional de Pesquisas Espaciais (INPE) em linguagem de macros denominada Linguagem Espacial para Geoprocessamento Algébrico (LEGAL). Na realização do trabalho foram seguidas as seguintes etapas:

A partir da rede hidrográfica, representada na base cartográfica, foi gerado o mapa de distância mínima aos cursos d'água de 30 metros em observância à alínea 2 do item (a) do artigo $2^{\circ}$ do Código Florestal. Também foi extraído o mapa de localização das nascentes, e a partir deste, calculada a distância mínima de até 50 metros, atendendo ao item (c) do artigo 20 do Código Florestal;

foi gerado um Modelo Digital de Elevação (Digital Elevation Model - DEM), pela metodologia da Rede Triangular Irregular (Triangular Irregular Network - TIN), a partir das isocotas altimétricas e da malha hidrográfica. Segundo CÂMARA e MEDEIROS (1998), este modelo permite uma melhor representação da variação do terreno, por captar a complexidade do relevo sem necessitar de grande quantidade de dados redundantes;

- a partir do modelo digital de elevação foi gerado o mapa de declividade;

- $\quad$ no mapeamento das áreas de uso e ocupação do solo, foram utilizadas as bandas: 3 $(0.63 \mathrm{~mm}$ a $0.69 \mathrm{~mm}), 4(0.78 \mathrm{~mm}$ a $0.90 \mathrm{~mm})$, $5(1.55 \mathrm{~mm}$ a $1.75 \mathrm{~mm}), 8(0.52 \mathrm{~mm}$ a 0.90 $\mathrm{mm}$ ) da imagem orbital do Landsat ETM. A resolução espacial foi melhorada pela transformação RGB/IHS, utilizando a banda 8 como valor de intensidade, conforme a metodologia descrita no manual do SPRING. $O$ resultado foi uma composição $R(4) G(5)$ $B(3)$, com resolução de 15 metros. Esta composição sofreu contraste e saturação, para que fosse visualmente melhorada, objetivando, a partir da interpretação visual, identificar as áreas com ocupação irregular dos fundos de vale, e

- $\quad$ por meio da linguagem de macro, denominada de Linguagem Espacial para Geoprocessamento Algébrico (LEGAL), foi utilizada a operação sobre geo-campos, de operação pontual, por operação booleana, para identificar as áreas de coincidência de uso e ocupação do solo com as de preservação permanente, ou seja, as áreas de ocupação irregular no perímetro urbano de Londrina.

\section{RESULTADOS E DISCUSSÃO}

A área urbana de Londrina se distribui em sua maior parte por locais planos (topos e divisores de água entre 0 e $10^{\circ}$ ), embora locais com declividades elevadas de até $30^{\circ}$ sejam ocupados. Distribui-se sobre um relevo que possui cotas altimétricas mais elevadas a noroeste (fronteira Londrina - Cambé), com altitudes aproximadas de $600 \mathrm{~m}$, e porções menos elevadas são encontradas na porção sul-sudeste, no vale do Ribeirão Esperança, com altitudes em torno de $450 \mathrm{~m}$. A direção predominante do relevo acompanha a direção preferencial da rede hidrográfica, controlada por lineamentos estruturais, no sentido noroeste-sudeste. A altitude da área urbana central é de $610 \mathrm{~m}$, e o seu sítio urbano distribui-se espacialmente sobre colinas suaves (Colina Verde, Pinheiros, Tucanos, Quebec, etc.) e espigões alongados que constituem os divisores de água 
secundários (Ribeirões Cafezal, Cambé, Lindóia, Jacutinga e Três Bocas), que desembocam no Rio Tibagi, no sentido leste (GRATÃO, 1989).

O relevo favoreceu o desenvolvimento da malha urbana em direção norte, leste e noroeste, cuja inclinação das vertentes é pequena e o relevo suave ondulado. Já a porção sul, com a elevada inclinação de suas vertentes, tornou-se um obstáculo para a expansão urbana, pois a ocorrência de vertentes com inclinação de $30^{\circ}$ ou até mesmo acima de $45^{\circ}$ é comum.

Dos $154,35 \mathrm{~km}^{2}$ de área total, não foi registrada nenhuma área com declividade acima de $45 \%$, em aten- ção ao item (e), artigo 2 e o artigo 10 do Código Florestal.

Áreas com declividade igual ou superior a 30\%, consideradas como áreas de uso restrito, conforme o Plano Diretor e regulamentado pela Lei $7.483 / 98$, somam um total de $5,39 \mathrm{~km}^{2}$ e estão localizadas principalmente na região sudeste da cidade ou nos fundos de vale. Estas áreas, juntamente com a de distâncias mínimas das nascentes e dos corpos d'água (figura 1), ou seja, as Áreas de Preservação Permanente, foram utilizadas como variáveis para compor o mapa de restrições legais e somam $21,36 \mathrm{~km}^{2}$ (figura 2).

FIGURA 1 - ÁREAS DE NASCENTES E DE CURSOS DE ÁGUA EM LONDRINA

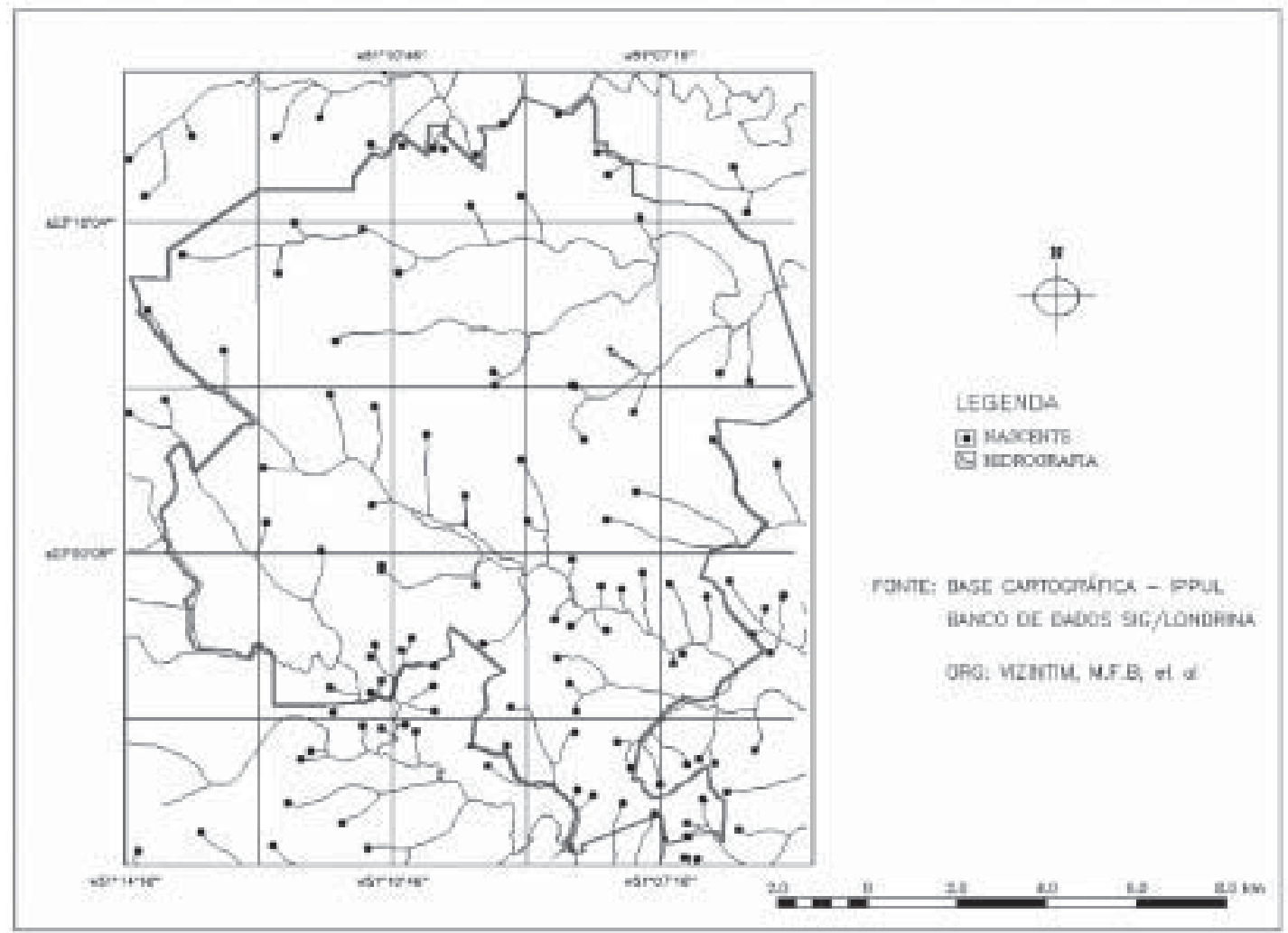


BARROS, M. V. F. et al. Identificação das ocupações irregulares nos fundos...

FIGURA 2 - ÁREAS DE PRESERVAÇÃO PERMANENTES EM LONDRINA

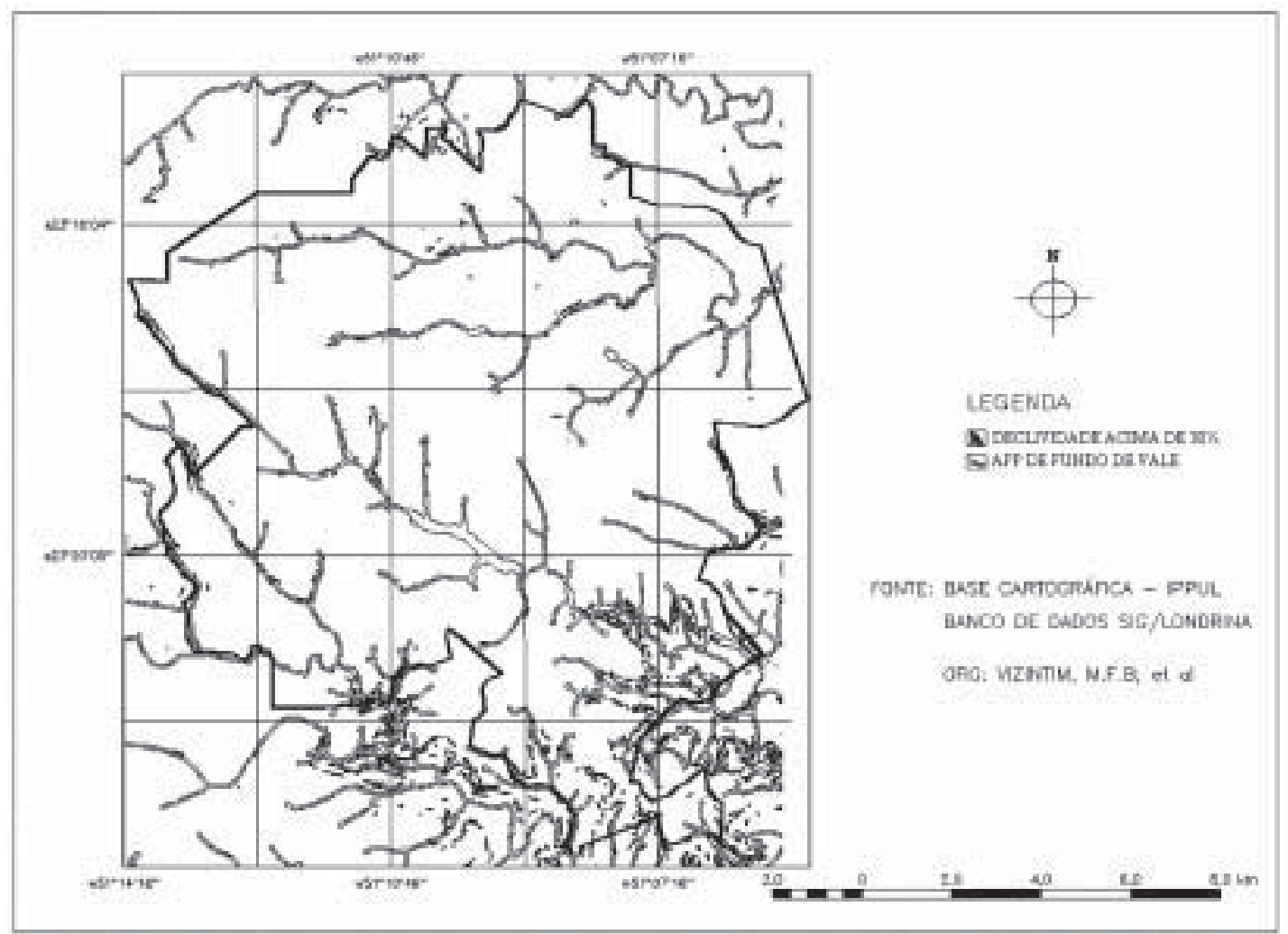

FIGURA 3 - ÁREAS OCUPADAS IRREGULARMENTE NO PERÍMETRO URBANO DE LONDRINA EM APPS

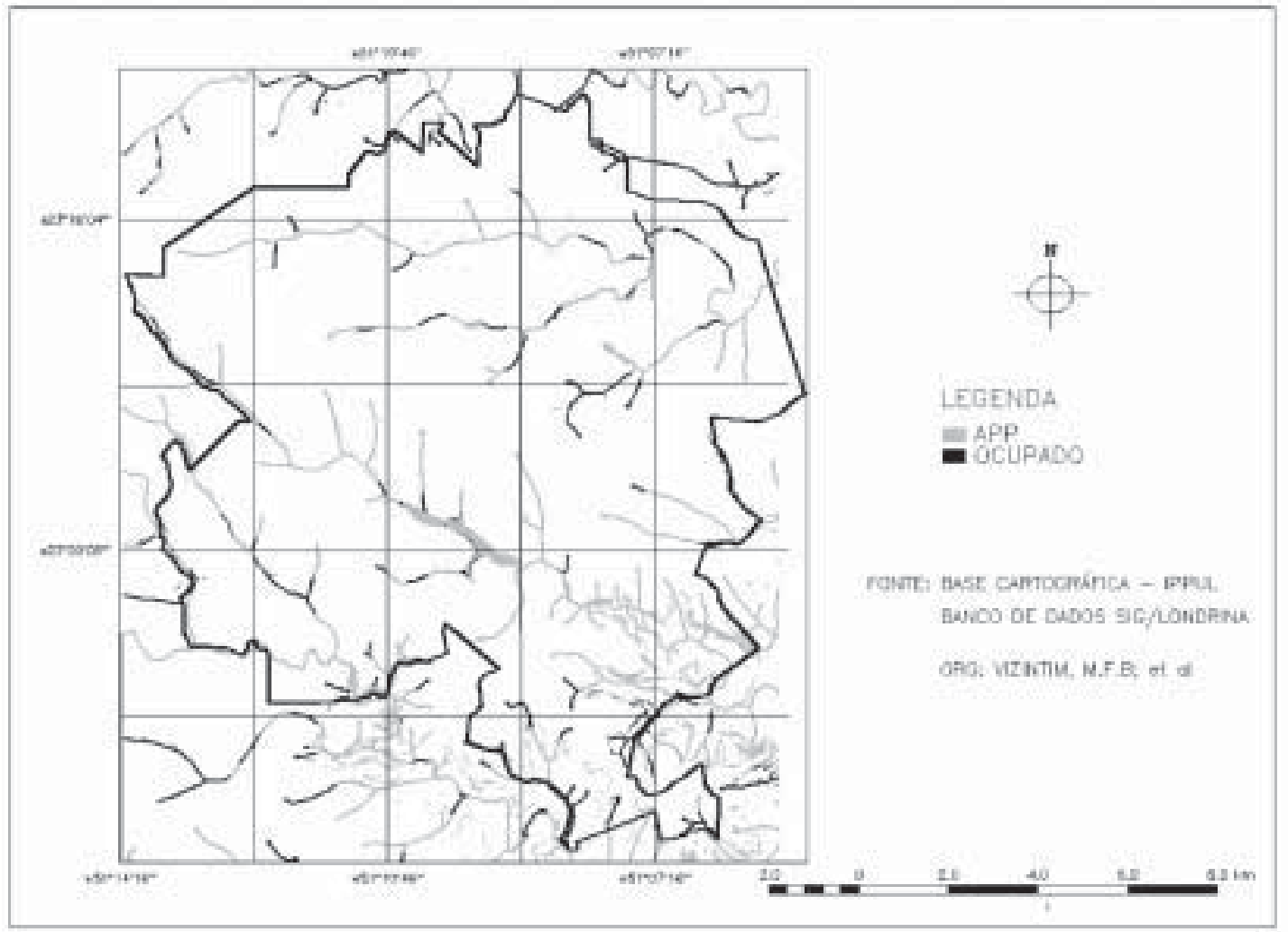


A comparação entre as áreas de restrições legais e as de uso e ocupação do solo permitiu definir as áreas de ocupação irregular no perímetro urbano, ou seja, $5,42 \mathrm{~km}^{2}$, o que corresponde a $25,4 \%$ das áreas de preservação permanentes em fundos de vale, encontramse invadidas ou ocupadas irregularmente (figura 3).

Conforme visto anteriormente, as áreas que margeiam os cursos hídricos, conforme o Código Florestal (1965), são consideradas "Áreas de Preservação Permanente" e pela Lei Federal n. ${ }^{\circ} 6.766 / 79$, que dispõe sobre o Parcelamento do Solo Urbano, consistem em área non aedificandi (de 15 metros de cada lado). Conforme a Lei Federal n. ${ }^{\circ}$ 7.803/89, deve ser respeitada ao longo dos rios ou de qualquer curso d'água desde o seu nível mais alto uma faixa marginal com uma largura mínima de 30 metros (aumentando conforme a largura do corpo d'água).

As leis de parcelamento do solo para fins urbanos e de uso, ocupação e expansão urbana (aprovadas em 07/1998) em Londrina definem as áreas de fundo de vale como "Áreas Especiais de Fundo de Vale e de Preservação Ambiental", devendo ser respeitadas as áreas ao longo das margens dos corpos d'água, numa largura mínima de 30 metros de cada lado. Esses locais teriam como princípio a proteção dos corpos d'água e destinar-se-iam prioritariamente à formação de parques contínuos, visando à preservação ambiental e recreação.

Embora a legislação existente seja suficiente para garantir a preservação dessas áreas, a ocupação irregular das APPs vem ocorrendo principalmente após os anos de 1970, promovidas por invasões e também pelo poder público municipal, que cedeu espaços em fundos de vales para entidades e associações, patrocinando a ocupação destes espaços. O Plano Diretor da cidade (Lei n. $.7 .483 / 98$ ), em seu art. 71ํㅡ, afronta a resolução do Conselho Nacional do Meio Ambiente (Conama) - (004/ 85), uma vez que o primeiro estabelece que "nos parcelamentos de áreas com frente para o lago Igapó I (entre a barragem e a Avenida Higienópolis), permite-se que os lotes tenham frente para a lâmina d'água, demarcando-se a faixa inedificável de $\mathbf{1 5 m}$ (quinze metros) a partir da margem", enquanto que a resolução do Conama, em seu art. 3 determina que "ao redor das lagoas, lagos ou reservatórios d'água naturais ou artificiais, desde o seu nível mais alto medido horizonte, em faixa marginal cuja largura mínima será de $\mathbf{3 0}$ (trinta) metros para os que estejam situados em áreas urbanas".

O crescimento desordenado da cidade trouxe uma série de problemas ligados à ocupação do espaço urbano, gerando uma cidade complexa, onde os vários atributos da natureza foram sendo degradados, criando injustiça e necessidades sociais prementes, afetando principalmente uma parcela da população menos favorecida. É necessária uma atuação mais eficaz do governo e também da iniciativa privada, para que haja urgentemente uma melhoria de condições de vida da população, principalmente a mais carente.

A legislação ambiental vigente é suficiente para que o meio ambiente e os recursos naturais sejam devidamente protegidos, porém falta o cumprimento destas leis pelas autoridades competentes. A divulgação das leis ambientais para a população, por meio de campanhas publicitárias, é um instrumento muito importante e poderá contribuir individualmente para a melhoria da qualidade ambiental e de vida da população, e ainda para uma melhor fiscalização e cumprimento da legislação vigente.

\section{REFERÊNCIAS}

BARROS, M. V. F. Análise Ambiental Urbana: estudo aplicado à cidade de Londrina PR. São Paulo, 1998. Tese (Doutorado) - Universidade de São Paulo.

BRASIL. Código Florestal (Lei no 4.771/1965). Governo Federal. Disponível em:<www.senado.gov.br> (Legislação Federal).

CÂMARA, G.; MEDEIROS, J. S. Mapas e suas representações computacionais. In: ASSAD, E. D.; SANO, E. E. (Eds.). Sistema De Informações Geográficas: aplicações na agricultura. Planaltina: Embrapa-CPAC, 1998. p. 13-29.

CARRARA, A. L. R.; FORESTI, C.; SANTOS, J. R. A distribuição dos espaços verdes em áreas urbanas: cartografia e análise comparativa entre dados TM/Landast e HRV/SPOT. In: ENCONTRO NACIONAL DE SENSORIAMENTO REMO-
TO APLICADO AO PLANEJAMENTO MUNICIPAL, 2., 1991, Serra Negra, SP. Anais...

CAVALHEIRO, F. Urbanização e alterações ambientais. In: TAUK, S.M. Análise ambiental: uma visão interdisciplinar. São Paulo: Unesp/Fapesp. 1991. p. 88-99.

GRATÃO, L. H. O sítio urbano de Londrina. Primeiras noções geomorfológicas. Departamento de Geociências, Universidade Estadual de Londrina, 1989. 4 p. Mimeografado

INSTITUTO BRASILEIRO DE GEOGRAFIA E ESTATÍSTICA. Censo demográfico do Brasil, Rio de Janeiro: IBGE, 2000. CD.

IPPUL (Instituto de Pesquisa e Planejamento Urbano de Londrina). Carta topográfica digital da área urbana de Londrina. Londrina, 1995. CD. 
BARROS, M. V. F. et al. Identificação das ocupações irregulares nos fundos...

MENDONÇA, L. B.; BARROS, M. V. F. Mapeamento da vegetação de fundo de vale da cidade de Londrina - PR , a partir de Imagens ETM LANDSAT. Geografia. Londrina: Departamento de Geociências da Universidade estadual de Londrina, v. 11, n. 1, p. 67-80, 2002.

MILANO, M. S. Planejamento da arborização urbana: relações entre áreas verdes e ruas arborizadas. In: ENCONTRO NACIONAL SOBRE ARBORIZAÇÃO URBANA, 3., 1990, Curitiba. Anais...
SOARES, J. J. Terminologia e caracterização da vegetação riparia. In: Programação e Resumos do 1ํ Simpósio Paranaense de Mata Ciliar, Maringá, 2000.

ZANINI, R. Espacialização do verde urbano em Londrina/PR. Londrina, 1998. Monografia (Bacharelado em Geografia) Universidade Estadual de Londrina. 